\title{
Evolution of Global IT Services Industry: Impact of Technological advancements and Business needs
}

\author{
Dr. K. Rangarajan ${ }^{1}$, Sushil K. Tiwari ${ }^{2}$ \\ ${ }^{I}$ (Prof. \& Head, Indian Institute of Foreign Trade, India) \\ ${ }^{2}$ (Research Scholar, Indian Institute of Foreign Trade, India)
}

\begin{abstract}
The global software \& services industry grew by $4.6 \%$ in 2012 to reach a value of $\$ 2,596$ billion. The compound annual growth rate (CAGR) of the industry in the period 2008-12 was 4.8\%. In 2017, the global software \& services industry is forecast to have a value of \$3,223.4 billion with an anticipated CAGR of $4.4 \%$ for the five-year period 2012 - 2017. Information Technology (IT) services are the largest segment of the global software \& services industry, accounting for $48.3 \%$ of the industry's total value. Americas account for $36.2 \%$ of the global software \& services industry. IBM is the leading player in the global software \& services industry, generating a 3.5\% share of the industry's value. This industry group is fragmented, with large incumbents operating alongside smaller companies, although diverse product portfolios and strong growth help to alleviate rivalry slightly. ${ }^{1}$

This paper attempts to trace the evolution of IT services industry, its current state, its challenges, mitigation of those challenges and a sneak peek at what the future has in store for this rapidly evolving area. The paper briefly discusses about the evolution of computing as a whole, the evolution of the graphical user interface, client-server architecture, and evolution of the internet, the current state of the IT industry and future prospects and outlook. It also touches upon several existing opportunities and challenges within this industry sector and space. New dimension segments such as Cloud, Big Data, Mobility and In Memory Computing are exciting new areas of research and development that have the capability to further revolutionize the industry. The study is rounded off by discussing challenges that exist within this sector and its future outlook.

The study is purely literature review based and is exploratory in nature. Reference materials include Journals, Government and analyst reports, white papers and web repositories.
\end{abstract}

Keywords: information technology, IT, innovation, technology, mobility, big data, cloud computing, dynamic environment

\section{Introduction}

Information Technology (IT) refers to any computerized command, communication, control and reporting systems that companies use to plan and operate their businesses. IT services refer to the development, implementation, configuration and support of computerized systems and tools that are used in the development and maintenance of such systems.

While the seeds of IT industry were sown much earlier with the technological advancements, it came into existence in early 1950s, as the first computers made their way into the business world with the introduction of IBMs first large computer, the IBM 701. After decades of slow but steady growth, the IT services market stood at USD 153 billion in 1990. Since then the IT industry has shown steady growth with few adverse years in between.

Worldwide IT spending had been projected to total $\$ 3.7$ trillion in 2013, a 2 percent increase from the 2012 spending of $\$ 3.6$ trillion, according to the forecast by Gartner, Inc. ${ }^{2}$

Table1. Worldwide IT Spending Forecast (Billions of U.S. Dollars)

\begin{tabular}{|c|c|c|c|c|c|c|}
\hline & $\begin{array}{l}2012 \\
\text { Spending }\end{array}$ & $\begin{array}{l}2012 \\
\text { Growth (\%) }\end{array}$ & $\begin{array}{l}2013 \\
\text { Spending }\end{array}$ & $\begin{array}{l}2013 \\
\text { Growth (\%) }\end{array}$ & $\begin{array}{l}2014 \\
\text { Spending }\end{array}$ & $\begin{array}{l}2014 \\
\text { Growth (\%) }\end{array}$ \\
\hline Devices & 676 & 10.9 & 695 & 2.8 & 740 & 6.5 \\
\hline Data Centre Systems & 140 & 1.8 & 143 & 2.1 & 149 & 4.1 \\
\hline Enterprise Software & 285 & 4.7 & 304 & 6.4 & 324 & 6.6 \\
\hline IT Services & 906 & 2.0 & 926 & 2.2 & 968 & 4.6 \\
\hline Telecom Services & 1,641 & -0.7 & 1,655 & 0.9 & 1,694 & 2.3 \\
\hline Overall IT & 3,648 & 2.5 & 3,723 & 2.0 & 3,875 & 4.1 \\
\hline
\end{tabular}

Source: Gartner (July 2013)

Researches have also shown that the Information Technology industry contributes 25 percent of the European Union's growth in GDP and 40 percent of its productivity growth currently. Within the ICT domain, 
considering the value of cloud computing alone, the aggregate sum is forecasted to exceed US $\$ 1$ trillion in Europe by 2020 . Global numbers also align in a similar way especially for the developed economies.

IT services have impacted the human lives in and out of offices, households everywhere in a major way. As per the World Bank report, Digitization, the mass adoption of connected digital services by consumers, enterprises, and governments, is a fundamental driver of economic growth and job creation all over the world. This is confirmed by econometric analysis that Booz \& Company conducted to quantify the actual impact of digitization on a country's economic output (GDP) and employment. Despite the continued sluggishness of economies across the globe, digitization boosted world economic output by nearly US $\$ 200$ billion and created 6 million jobs in $2011 .^{3}$

IT services have historically been built either for the business functions like HR, Supply chain, Finance etc. or for the industries like manufacturing, Pharmaceuticals, Retails etc. till now. New technologies like Cloud computing, Big data, Mobility and In memory computing are redefining the way IT industry serves the business. It remains to be seen whether a convergence is on the anvil in the future or IT services would altogether take a new direction.

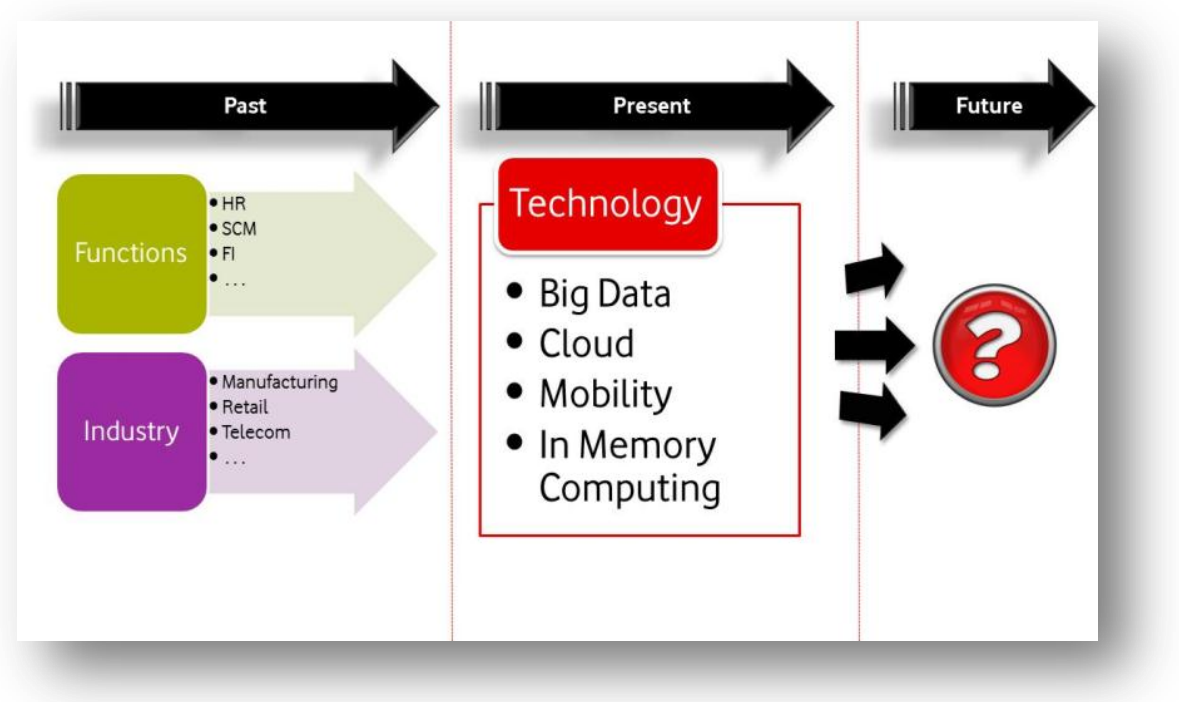

Source: Creation by the Author

Though the IT services industry has seen massive advancements and has optimized the ways of working all over, the industry has not been untouched by challenges. Some of the teething ones are uncertainties in the economic environment, data privacy and security issues, mismatch in the skills, legislation impacts, market fragmentation, talent retention, churn, rising compensation, infrastructure availability etc.

The major transformation fuelled by business applications has just started. It is about holistically managing the economic, environmental, and social implications of business-what we call sustainability. Sustainability is already changing our lives, bringing with it new business models, new winners, new losers, together with completely new ways to operate. Today, chief executive officers are just waking up to this reality, and most struggle to implement a sustainability strategy. However, as with globalization and e-commerce, incorporating sustainability into their business strategy and using business applications to drive this transformation is essential for companies to be competitive ${ }^{4}$.

\section{Emergence of the IT and IT Services industry}

Like any other industry, IT industry also evolved over a period of time. However, the stages of evolution have been phenomenally fast.

\subsubsection{Technological evolution of the IT industry:}

2.1.1.1 The first calculator: The abacus is thought to have been originally invented 3000 years before the birth of Christ. Revisions to its use/design continued for many years, e.g., around $500 \mathrm{BC}$, a bead and wire version was developed in Egypt. Early versions of the calculator gradually replaced this primitive method of mathematics. In 1624, Wilhelm Schickard built the first four-function calculator-clock at the University of Heidelberg. The first general purpose calculator/computer was designed by Charles Babbage around 1833.In 1855, George and Edvard Scheutz built a practical model based on Babbage's original designs. The first electronic calculator (named the Z1) was built by Konrad Zuse in 1931. In 1940 at Bell Labs, the Complex 
Number Calculator was tested and then demonstrated. This is thought to have been the first digital (pulse wave rather than analogue wave run) computer.

2.1.1.2 The evolution of computers / laptops and networks: In 1971 Intel Corporation released the first microprocessor (the Intel 4004.)The PC as we know it today was created by IBM and released in 1981. Apple introduced its PC alternative, the Macintosh, in 1984. It features a GUI (Graphical User Interface) which gave the IBM PC's DOS (text-based) run system stiff competition due to its usability and professional software. The World Wide Web was developed by Tim Lee in 1991, and CERN also created the first Web Server in 1993.The Pentium chip was included in PCs for the first time in 1993 signalling the end for the 486 chip in use at that time. A supercomputer - the most advanced type of computer (or collection of computers in one large tower) was available for the first time via IBM's ASCI Purple.

2.1.1.3 The advent of the Graphical User Interface (GUI): Doug Engelbart and his team at the Stanford Research Lab developed the first mouse in 1968. In 1973 the first computer with a mouse-driven GUI was developed. This never became a commercial product. Steve Jobs took over the concept and directed Apple to improve upon it. In 1984 Apple introduced the Macintosh, the first mass-market computer with a graphical user interface and a mouse. IBM was dominating the PC market till then with their IBM PC introduced in the 80s. Microsoft provided an operating system for the IBM PC known as "DOS" or "Disk Operating System" which was non-graphical in nature. Apple introduced the Macintosh with a GUI and Mouse, to dislodge IBM's dominance in this space. In response, Microsoft developed its own PC-compatible Windows operating system which had its own graphical GUI.

2.1.1.4 The invention of the Client server architecture: Client server computing models began to rise in prominence in the beginning of the 1990s. With this invention, information technology became not just about processing transactions and handling content, but about connecting an organization's processes. Computers now connected people together in new ways; the distinctions between computing, communication and content or knowledge began to blur. Client server technologies broke down organizational barriers and put knowledge into the hands of knowledge workers. ${ }^{5}$

Business application technology became the power to drive global transformations. It progressed from mere recordkeeping to being the key to worldwide, irreversible, and fundamental change. The first major transformation advanced by business applications was globalization. Technologies supported by the clientserver model of networked and distributed computing, for example, enabled executives to close books on a global scale and consolidate data quickly. Companies could manufacture products in one market and sell them in another without having to locate offices in either.

\subsubsection{Evolution of the Internet}

There has been officially World Internet Connectivity since $15^{\text {th }}$ Jun 1995.An Internet application is software that allows its users to execute business logic using a universal, client-server browser architecture (Conallen 2000). Business to consumer Internet applications directly interface with customers and constitute the product or service offered to them.

Resource sharing facilitates economies of scale and pay-as you-go pricing. Multi-tier clustering allows an online service provider to more easily scale up and grow the business. And, application customization can differentiate the provider from other providers.

New types of applications drove significant change through disintermediation, putting more power than ever into the hands of consumers. The new paradigm created giants such as Google, Amazon, and eBay and is now changing the very way business applications are consumed by delivering them as services in themselves. The transformative power of business applications has run so deep that it touches the way we all work, the way we communicate, and the way we consume. Today, companies' competitiveness relies on their ability to tap into the connective power of the internet.

For enterprises, applying IT to their operations significantly improve their operational efficiency. In an increasingly flat world, the potential customer base for many enterprises is extremely broad and the environments in which they operate are very complex. These enterprises inevitably confront declines in efficiency and increases in costs. Innovative IT technologies can help solve these issues, e.g., cloud computing can reduce the cost for information-based enterprise operations, and the internet can deliver smarter management systems. 


\subsection{Business view of the IT services industry}

\subsubsection{How the industry is organized / structured?}

At the highest level the global software and services industry is divided into Information Technology and Communication. While Information Technology area covers, Services, Software, Digital media and Hardware; Communication covers the areas of Service provisioning and Network equipment. Managed services, Integration services, Support services and Online services are the sub classification of services, whereas, the Packaged Applications services fall under the software area.

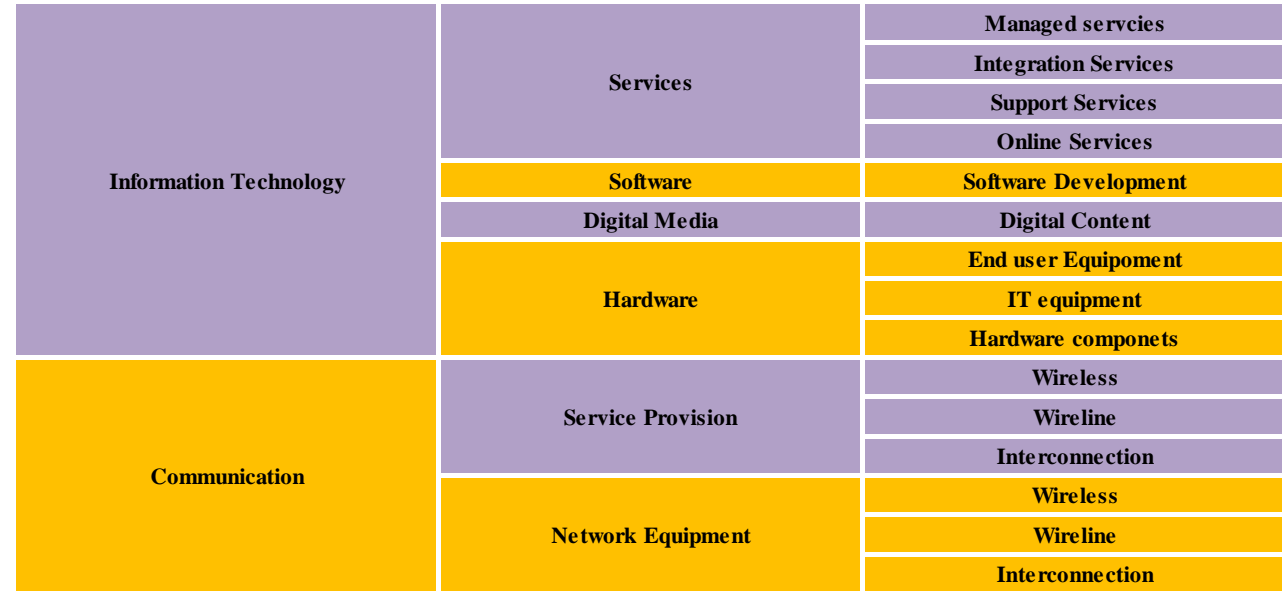

Source: World Economic Forum report; re-creation by the Author

\subsubsection{Growth in the IT services industry}

The global software \& services industry group had total revenues of $\$ 2,596$ billion in 2012, representing a compound annual growth rate (CAGR) of 4.8\% between 2008 and 2012.

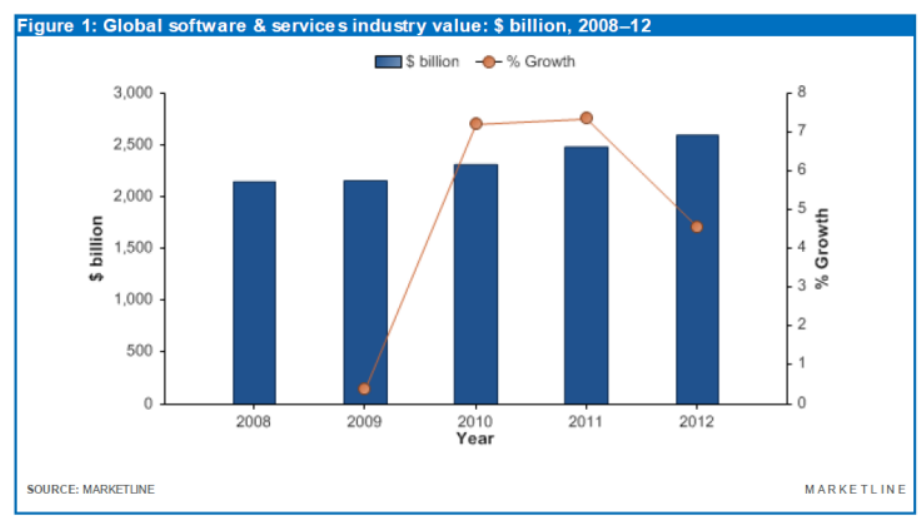

The information technology (IT) services segment was the industry group's most lucrative part in 2012, with total revenues of $\$ 1,254.3$ billion, equivalent to $48.3 \%$ of the industry group's overall value. The internet software \& services segment contributed revenues of $\$ 1,047.3$ billion in 2012 , equating to $40.3 \%$ of the industry group's aggregate value.

The performance of the industry group is forecast to decelerate slightly, with an anticipated CAGR of $4.4 \%$ for the five-year period $2012-2017$, which is expected to drive the industry group to a value of $\$ 3,223.4$ billion by the end of 2017 .

\subsubsection{Porter's Five Forces Analysis as applied to the IT services industry}

Buyers in this industry group range from small, individual customers to businesses and government entities. The loss of business from a larger buyer could have a negative effect on players' revenues, boosting buyer power. Suppliers tend to be large companies, and players' reliance on supplier inputs means supplier power is strong. New entrants may be put off by industry regulations and competition faced from large, multinational incumbents. However expected growth may mitigate the rivalry level to some extent making the market more appealing to new entrants. 


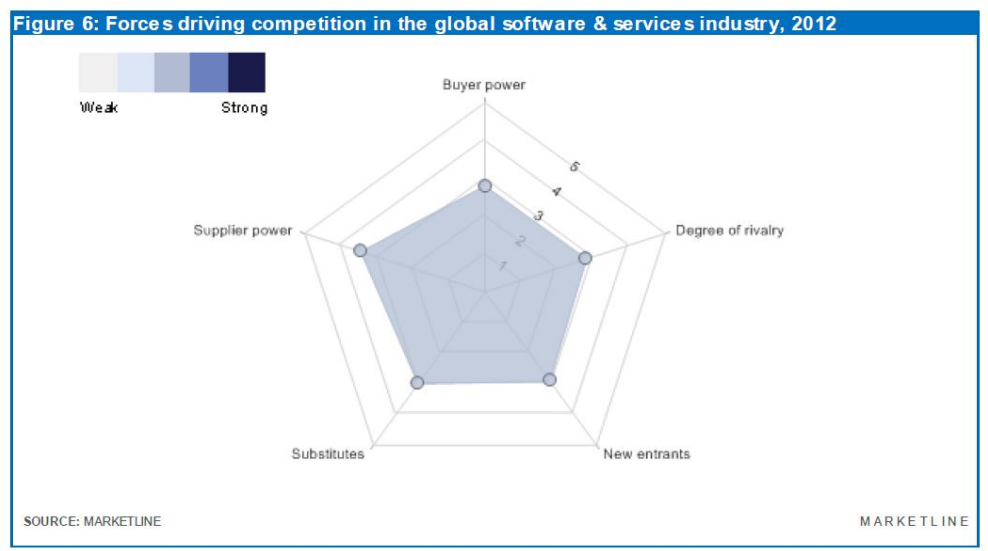

\subsubsection{Networked Readiness Index (NRI) as Measurement of IT growth}

The Networked Readiness Index (NRI) aims to measure the ability of countries to leverage information and communication technologies (ICTs) for improved competitiveness and wellbeing. The NRI results ${ }^{8}$ confirm the presence of the digital divide between advanced economies on the one hand and emerging and developing economies on the other. Following graph shows the NRI (across different segments) in Advance as well as Emerging \& Developing economies.

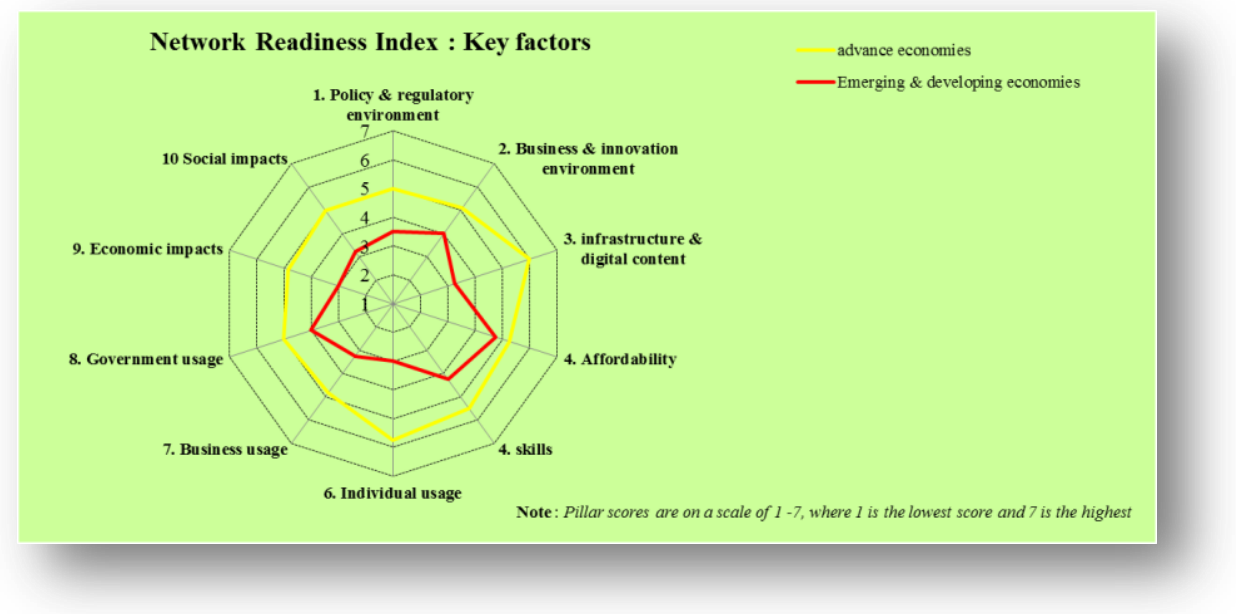

Source: World Economic Forum report; re-creation by the Author

\subsubsection{Leading Players}

IBM leads the pack of Global software and services companies in terms of the share by value with $3.5 \%$ share. Microsoft, HP and Google follow respectively. Interesting fact is that the top four total up to only around $10 \%$ of the share indicating the fragmentation and large number of players in the space ${ }^{1}$.

Table 2. Global Software $\&$ services industry share : \% share, by value, 2012

\begin{tabular}{ll}
\hline Company & $\%$ share \\
\hline IBM & $3.5 \%$ \\
Microsoft corporation & $2.5 \%$ \\
Hewlett-Packard company & $2.3 \%$ \\
Google Inc. & $1.8 \%$ \\
Other & $90.0 \%$ \\
\hline \hline Total & $\mathbf{1 0 0 . 0 \%}$ \\
\hline
\end{tabular}

\subsection{Future of IT Services}

Existing literature indicates that future of IT services clearly seem to be resting on the new technology areas of cloud computing, Mobility, Big data, In Memory Computing etc. 


\subsubsection{Cloud Computing}

The past few years have seen the emergence of a new megatrend called cloud computing. It involves providing IT solutions as a service over the web instead of the customer owning and buying the IT solution per se. It consists of a large group of interrelated computers.

Cloud computing provide organizations with the possibility to move their computing requirements to a shared platform and buy applications or infrastructure as a service. This new model is expected to provide organizations with considerable savings and also service flexibility. This trend is transforming IT to a utility industry in the same way as water or electricity, which is also provided as utilities by utility providers - charges are based on actual usage.

The market for cloud-based services was $\$ 16$ billion in 2008, and projections estimate the market for spending in this area will reach $\$ 42$ billion by $2012 .{ }^{6}$

The rise of cloud computing has reduced the competitive differentials in technology availability across larger and smaller firms. High availability of data is implicit in any cloud computing solution. Thus server crashes can be made redundant and networks can effectively recover from such outages. ${ }^{7}$

\subsubsection{Mobility}

Mobile Broadband is redefining internet access and empowering individuals. With more than 6 billion connections worldwide and US $\$ 1.3$ trillion in annual revenue, mobile telephony has become the largest ICT in history. Mobile connects four times as many people as landline telephony because of its better reach, convenience, and functionality, as well as its lower costs. Mobile telephony also surpasses the landline Internet by more than 3.5 billion users, while driving economic growth and important societal benefits. ${ }^{8}$

Across the developing world, mobile phones are routinely used not only for personal communications, but also to transfer money, to search for work, to buy and sell goods, or transfer data such as grades, test results, stock levels and prices of various commodities, medical information, etc.

According to Gavin Krugel, director of mobile banking strategy at GSM Association, an industry group of more than 800 wireless operators, "about 40 million people worldwide use mobile money and the industry is growing.'

Mobile broadband, or high-speed access to the internet and other data services over mobile networks, is already changing the way people across the globe access the internet. It promises to drive even stronger economic growth than mobile telephony alone and is going to fundamentally change the way in which we live, learn, work, and collaborate.

Internet traffic is expected to grow 25-30\% between 2011 and 2015 in North America, Western Europe and Japan, and the bulk will come from mobile devices.

\subsubsection{Big Data}

"Big Data" is a popular phrase used to describe a massive volume of both structured and unstructured data that is so large that it's difficult to process with traditional database and software techniques. The characteristics which broadly distinguish Big Data are sometimes called the " $3 \mathrm{Vs}$ ": more volume, more variety and higher rates of velocity.

The world is experiencing a revolution of data deluge. Whereas in previous generations, a relatively small volume of analog data was produced and made available through a limited number of channels, today a massive amount of data is regularly being generated and flowing from various sources, through different channels, every minute in today's digital age. It is the speed and frequency with which data is emitted and transmitted on one hand, and the rise in the number and variety of sources from which it emanates on the other hand, that jointly constitute the data deluge.

The amount of available digital data at the global level grew from 150 exabytes in 2005 to 1200 exabytes in 2010. It is projected to increase by $40 \%$ annually in the next few years, which is about 40 times the much-debated growth of the world's population. This rate of growth means that the stock of digital data is expected to increase 44 times between 2007 and 2020, doubling every 20 months ${ }^{9}$.

Beyond the availability of raw data alone, and beyond the intent to utilize it, there needs to be capacity to understand and use data effectively. In the words of Stanford Professor Andreas Weigend, "data is the new oil; like oil, it must be refined before it can be used."

\subsubsection{In memory computing}

The use of in-memory technology marks an inflection point for enterprise applications, especially in dealing with big data. The availability and capacity per dollar of main memory have increased markedly in the last few years. This growth has led to a rethinking of the way mass data should be stored. Instead of using mechanical disk drives, it is now possible to store a primary database in silicon-based main memory, resulting in 
an orders-of-magnitude improvement in performance and enabling the development of completely new applications.

In-memory analysis and reporting delivers rapid access to visually rich, interactive dashboards that anyone can build quickly and modify easily. It enables users to see and know their businesses in new ways and interactively explore data without limits. Now, users can engage their data with blazing speed, resulting in more informed, proactive decisions. For IT departments, it means far less time spent on query analysis, cube building, aggregate table design, and other time-consuming performance-tuning tasks.

The in-memory approach is not new. The desire to take advantage of the speed of RAM has been there for some time. However, the promise became a reality only recently, thanks to the mainstream adoption of 64-bit architectures that enable larger addressable memory space and the rapid decline in memory prices. Because of this rapidly changing infrastructure landscape, it is now realistic to analyze very large data sets entirely inmemory.

The benefits of in-memory analytics include dramatic performance improvements, cost effective alternative to data warehouses and discover new insights to optimize business performance.

\section{Conclusion}

Some of the high level generic challenges plaguing the industry are Infrastructure (broad band, cables/telephony), data security issues, fragmented market for IT services, Talent retention, Employee Churn, ever rising Compensation and dynamic economic situation.

These challenges have made the IT industry turbulent during the last several years, and governments and enterprises have been doing everything possible to inject momentum and ensure sustainable growth

On one side, the impact of IT on other industries has become more far reaching as its transformational effects spread to several sectors of the economy and society via innovations, the emergence of new industries, and the advent of the era of hyper-connectivity. On the other side, the strategy and operations in IT are influenced by two sets of factors. The first sets of factors are internal to the organization. The other set of factors are dependent on external entities and are mostly out of control for the services vendor organization. The broad areas that affect the IT industry strategy formulations turn out to be environment, financials, people, processes, structure, governance and technology etc. ${ }^{10}$

For enterprises, applying IT to their operations significantly improves their operational efficiency. In an increasingly flat world, the potential customer base for many enterprises is extremely broad and the environments in which they operate are very complex. These enterprises inevitably confront declines in efficiency and increases in costs. Innovative IT can help solve these issues, e.g., cloud computing can reduce the costs for information-based enterprise operations, and the internet can deliver smarter management systems.

The links between IT tools, services, and models and the importance of competitiveness, growth, and jobs have never before been the subject of so much attention and concern. On the pull side, this is not surprising that developed economies need to reinvent themselves to maintain or restore their competitiveness, retain or regain market shares, and create jobs. Whereas, emerging and developing economies are seeking ways to improve productivity and find new sources of growth through new technologies. The world also needs to collectively address environmental and social challenges to ensure a more sustainable development path and a better quality of life for its people.

On the push side, technological progress continues at a relentless speed. The growing availability of technology has empowered people with fairly good access to the digital world. The rise of cloud computing has reduced the competitive differentials in technology availability across larger and smaller firms. It is clear that IT offers higher benefit-to-cost ratios in all sectors of production by offering new ways to create value through better and more efficiently organized use of natural, financial, and human resources.

Another aspect that comes out very clearly in the available literature is that the 3 key stakeholders of IT - the Product organizations that develop the solutions, System Integrators who provide IT solutions and the customers who use the IT services, all have different drivers to leverage IT. 


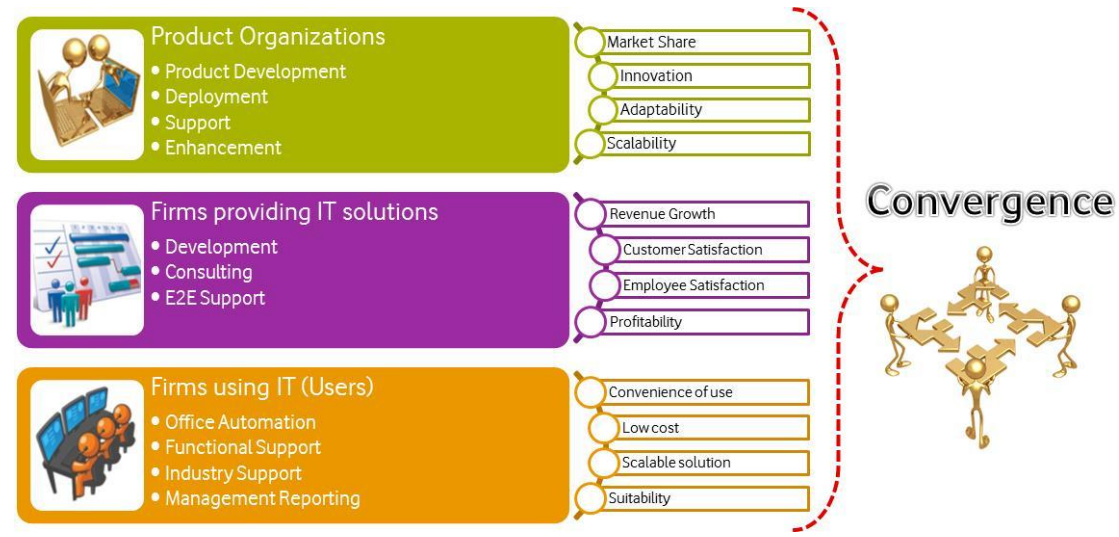

Source: Creation by the Author

While market share and innovation broadly drive the strategy for product organizations, System Integrators focus more on the revenue growth and profitability alongside satisfying the customers as well as employees. For the users of IT services, convenience of use, cost efficiency, suitability and scalability etc. play the most important role in deciding which product and services to go for.

With the future of IT looking focused around innovation and sustainability, it would be interesting to see if there would be a convergence of the way the stakeholders of IT services look at IT.

\section{References}

[1]. Market Line Industry Profile, Global Software \& Services, October 2013

[2]. Rob van der Meule; Gartner, IT Spending Forecast, 2Q13, July 2013

[3]. Beñat Bilbao-Osorio, Soumitra Dutta, and Bruno Lanvin, The Global Information Technology Report, 2013

[4]. The Global Information Technology Report 2009-2010 (C) 2010 World Economic Forum

[5]. Mark Goodyear; Enterprise System Architectures: Building Client Server and Web Based Systems

[6]. FarheenAltaf, David Schuff; Taking A Flexible Approach to ASPs; Communications of the ACM, Vol. 53, No. 2. Feb 2010

[7]. Konijeti Meghana, Y. Madhavi Latha, V. Samson Deva Kumar, Suresh Angadi;Methodology of Cloud Computing; International Journal of Emerging Science and Engineering (IJESE,) Vol-1, Issue-5, Mar 2013

[8]. World Economic Forum's Global Information Technology Report 2008-2009: Mobility in a Networked World and other research.

[9]. World Economic Forum's Global Information Technology Report 2012

[10]. Dr. K. Rangarajan, Sushil K Tiwari; Packaged Software Application Services Industry: Evolution and the factors affecting the industry; IOSR Journal of Business and Management (IOSR-JBM), Volume 16, Issue 4. Ver. V (Apr. 2014), PP 33-38 